Rupkatha Journal on Interdisciplinary Studies in Humanities (ISSN 0975-2935), Vol. 10, No. 1, 2018 Special Issue on "Interrogating Cultural Translation: Literature and Fine Arts in Translation and Adaptation" In collaboration with the Department of English, Amrita Vishwa Vidyapeetham Guest-edited by Dr. Hari M G, Amrita Vishwa Vidyapeetham, Coimbatore, India DOI: https://dx.doi.org/10.21659/rupkatha.v10n1.03 Full Text: http://rupkatha.com/V10/n1/v10n103.pdf

\title{
Using Untranslatable Dictions as a Literary Device
}

\author{
Rajendran Sankaravelayuthan \\ Centre for Excellence in Computational Engineering and Networking (CEN), Amrita Vishwa \\ Vidyapeetham. Email: s_rajendran@cb.amrita.edu.
}

Received September 27, 2017; Revised December 11, 2017; Accepted December 30, 2017; Published February $04,2018$.

\begin{abstract}
This paper intends to analyse the writings of Indian novelists and find out how they make use of untranslatable dictions as a literacy device. Indian writers often choose Indian situations or Indian themes while resorting to create a literary piece in English. One can find Indianism in the writings of all the Indian English authors. We come across many novelist of early period as well as the present period choose a theme familiar to them by place, culture and acquaintance and build their characters and stories so that the stamp of Indianism is imprinted in their writings. While going through the writings of Indian authors, of early period such as R. K. Narayan, Ahmad Ali, Raja Rao and Mulk Raj Anand and the present day Arundathi Roy, Anita Nair, Amish Tripathi, Chetan Bagat, Sudeep Nagarkar and others, we can observe that they codify English to suit their intention of narrating stories with Indianism. They resort to a unique deviation at all the levels of language structure such as discourse level, syntactic level, lexical level, morphological level and phonological level. Code mixing is the major strategy they adopt. They make use of untranslatable dictions to present before their readers an Indian menu to consume. The outcome of their efforts becomes artificial or artificially code mixed. The language spoken by their characters may not exist in the real world. So they make a distinction between the textual world and real world. The textual world allows the use of artificial English loaded with cultural terms or untranslatable items.
\end{abstract}

Keywords: Indianism, untranslatability, code mixing, lexical deviation, morphological deviation, syntactic deviation, discourse deviation, phonological deviation, cultural translation

\section{Introduction}

The question of untranslatability arises when the translator is unable to find out a translation equivalent for the source language unit in the target language. It is difficult to say that an item or unit is exclusively translatable or exclusively untranslatable. The degree of difficulty in translating one into another depends upon the nature of the source text and also on the skill of the translator. Generally an item is said to be untranslatable if the translator finds it out as a lacuna or lexical gap in the target language. It is very difficult to say that there is always one-to-one correspondence the between the source and the target language for all the units under consideration. A number of translation procedures are available to a translator to overcome this lacuna. Therefore, untranslatability or difficulty of translation does not always carry deep linguistic relativity implications. Denotative meaning can be easily carried from source language to target language. But connotative meaning is difficult to transfer from source to target language.

(C) Authors. Published by AesthetixMS under a Creative Commons Attribution Non-Commercial 4.0 International License (http://creativecommons.org/licenses/by-nc/4.0/). 
The translation procedures that are available to a translator to overcome the untranslatability or lexical gaps include the following: adaptation, borrowing, calque, compensation, paraphrase, translator's notes, and register.

The purpose of this paper is not to explore the untranslatability of culture loaded linguistic expressions, but to discuss about how cleverly the English writers of Indian origin manipulate untranslatability to present a unique style in their works. They make use of an English diction which is quite artificial and sugar quoted by the untranslated cultural terms or expressions so as to make their writings different form that of native English writers. The untranslatability has been exploited by them as the style of their writings. Starting from R. K. Narayan, Ahmad Ali, Raja Rao and Mulk Raj Anand, who are the pioneers of Indo-Anglian fiction, I have travelled through the present day Arundathi Roy, Anita Nair, Amish Tripathi, Chetan Bagat and his contemporaries, say for example Sudeep Nagarkar and others. Most of them with the exception of a few make use of a diction which is quite artificial and unavailable as language spoken in any context. Such artificial English language has been floated by them to make their writings look like something unique with Indian flavour. The discourse or dialogues used by the characters are artificial in the sense that you will not be able to find a person talking in that sort of English in a day-today face to face contacts in Indian situation. The characters in the writings are bound to talk in an artificial English language with the belief the readers will consider it normal as the stories are wound around Indian situations. Here in this paper I would like to explore how these English writers of Indian origin successfully present before us a sort of English which is consumed as Indian English or English flavoured by Indian masala. These writers belong to a different genre compared to E.M. Foster and Jim Corbett who are British writers and who took topic of Indian milieu.

\section{Indianism in The Writings of Indian English Authors}

Crystal (2006) in "Words, Words, Words" opines that the vocabulary of a language is a salad bowl of words of different kinds and backgrounds. Novels provide the best examples of this image of language as a salad bowl consisting of a plethora of words selected carefully by the authors to narrate their stories. "Language has no life of its own: it only exits in the mouths, ears, hands and brains of its users," thereby it can be construed that each word chosen with great care by the author invites the readers to "engage linguistically with who we are." (Crystal 2006:1). The Indian writers of English stand to exemplify Crystal's statement mentioned above.

We can distinguish two genres of Indian English writers, those belonging to the preindependence period and those belonging to post-independence period. R. K. Narayan was a leading author of early Indian literature in English along with Mulk Raj Anand and Raja Rao. He was an Indian writer known for his works set in the fictional South Indian town of Malgudi. Kachru (1995: 293) says that Rao, Anand and R.K. Naryan "have brought another dimension to the understanding of the regional, social and political contexts. In this processes, linguistically speaking, the process of the Indianization of English has acquired an institutional status". R.K. Narayan employed the use of nuanced dialogic prose with gentle Tamil overtones based on the nature of his characters. Most of Narayan's work, starting with his first novel Swami and Friends (1935), captures many Indian traits while retaining a unique identity of its own. Raja Rao consciously makes use of 'nativised' English language. He "appropriates English language on Indian terms, and the language legitimizes itself in India's sociocultural context" (Kachru, 2005: 143). Mulk Raj Anand had also experimented with the English language in his own way, 
incorporating his own individual style of language. But "One important difference between the styles of Raja Rao and Anand is that Anand's experiments are limited to the dialogue of his characters; while Raja Rao's special effects permeate his entire style" (Mukherjee, 1971: 186).

Anita Desai, Rohinton Mistry, Amit Chaudhari, Vikaram, Seth, Arundhati Roy, Kiran Desai, Arvind Adiga and a steam of authors belong to the second genre. The recent generation of Indian English authors includes Makarand Paranjape, Arundhathi Subramaninam, Chitra Divakaruni, Jaishree Mishra, Jeet Thayil, Anita Nair, Anees Salim, Jerry Pinto, Meena Kandasamy, Rukmani Bhaya Nair, Chetan Bhagat, Vikas Swarup, Sudeep Nagarkar and a flow of authors belong to this group.

Arundhati Roy has sprinkled Malayalam words, phrases and names throughout her novel God of Small thing. Roy's innovative and unique use of the English language in her God of Small things won her the Brooker Prize. The idiom that Roy employs perfectly matches with the theme she is concerned with.

There are migrant English writers who write on Indian oriented subjects. They can be considered belong to the third genre. Salman Rushdie, V.S. Naipaul, Rohinton Mistry, Uma Prameswaran, Sujatha Bhat, Bharathi Mukherjee, Meena Alexander, Jhumpa Lahiri and a row of writers belong to this genre. Salman Rushdie claims to have invented a kind of hybrid Indian English language which he termed "chutnifed" English which is English liberally sprinkled with Indian words. "The 1981 publication of Salman Rushdie's Midnight's Children was a watershed in the post-independence development of the Indian English novel, so much so that the term "postRushdie" has come to refer to the decade or so afterwards in which a wave of novels appeared by established as well as by young writers that were clearly influenced by Midnight's Children." (Rege, 1997). Kachru (1996: 149) points out the suspicion of the critics about the nationalistic, linguistic and cultural roots of Indian immigrant writers and their doubt about the appropriateness of the use of a non-native language for recreating typically Indian social, cultural or emotional contexts. Spivak (1990) makes a vehement criticism against these diasporic writers: "Generally in diasporic English fiction written by people who have no active contact with the native languages, the only way in which these native languages are denoted is through the monstrous mockery of a transformed standard English which reflects more the writer's lack of creative access to the languages of the country" (Spivak 1990: 219-244).

Bandyopadhyay (2007) emphasizes on the concept of Indian English as a specific variant of International Standard English. Her analysis of specific texts which is a global approach (both local and global), stresses the common features of vocabulary, loan-translation, use of repetition, formality of register and linguistic creativity. She has identified six linguistic factors of Indian English.

1. transfer of context

2. transfer of L1 (an Indian language) meanings to L2 (English)

3. transfer of form-context component

4. grammatical deviation

5. Indian expressions and terms

6. Hybrid Indianism (Bandyopadhyay 2010:129)

The following quotes form Bhatnagar, 1996) is worth considered here: "Indian English writers work obviously work under a kind of creative tension with which writers writing in their 
native languages are not confronted. Besides the tight rope walking on the linguistic front, Indian English writers have to contend with another difficult choice: writing for a foreign as well as native clientele, the former require them to explain uniquely Indian thoughts and situations, the latter treating such explanation of the obvious as inartistic and an excrescence .placing the writer on the horns of a uniquely a situational dilemma." (Bhatnagar, 1996: 1-2). "The Indian English writer has to choose his own blend of tradition both Indian and English -and individual talent, the capability to synthesize them and forge his experience into a unique artistic amalgam meeting the dual requirements-an inevitable and exacting requirement incontrovertibly." (Bhatnagar, 1996: 1-2)

\section{Untranslatablity as a Literary Device}

I have taken into consideration only the writings of a few contemporary authors to prove my premise that untranslatability is used as a literary device by the Indian English authors.

Indian writers of one school of thought did not employ the practice of mixing regionalIndian English forms and preferred minimum lexical, semantic or proverbial borrowing. But the situation has changed and is different today as Indian English has evolved into a distinct language with a large number of variants scattered across the subcontinent, even suggestive of a particular regional or class dialect or personal idiolect.

As pointed out earlier, the Indian English authors make use of cultural dictions as such in order to give an Indian flavour to their writings. Starting from R.K. Narayan till Chetan Bagat, you will see that they make use of the untranslatable dictions or culture loaded words or phrases as a part of their literary style. The proportionate quantity of this mixture varies from author to author. The very selection of their story location in a place in India, say for example a village, demands the use of such dictions in their story.

You will find culture loaded terms or words such as shikari, pujari, bharatnatyam, karma, darshan and so on in R.K. Narayan's works (say for example in "A tiger of Malgudi." The very fact that R.K.Narayan's stories roam around Malgudi itself demands such culture loaded dictions, which I call untranslatable dictions. The selection of location, of course demands selection of personal names and proper names belonging to the place of the plot. This also adds Indian native flavour to the style of their writings.

The story of "Mistress" of Anita Nair is set in an environment where the main language used in the real world is obviously Malayalam. In the text world it is assumed that the main characters (sometimes all the characters) converse in English. I will place Anita Nair in the position of an author who adds more number of Indian native words; say Malayalam words, by compulsion or default. As her novel "Mistress" plotted around the lives of certain characters, and one of them being a former kathakali artiste, she profusely makes use of untranslatable dictions in her said novel. Through "Mistress" she talks about navarasas, which itself is a culture loaded word. She makes use of unglossed titles such as Sringaaram, Haasyam, Karunam, Rudhram, Veeram, Bhayaanakam, Beebhalsam, Adbutam, and Shaantam, The titles have been deliberately used to evoke an aesthetic Indian cultural ethos and endow the following sections with an exotic and mystical aura.

In her written piece of work "Idris" Anita Nair makes use of dictions from Arabic and Somali languages. The prologue of "Idris" is strewn with Arabic and Somali names of people and places, and other lexical items. 
abaayo amiino jijineey rabtaaye, aabe majoogto - Fatima Naaya, singing a lullaby softly to the yound Idris (Nair 2014:3)

Al-Zahra, the lamp of evening sky (Nair, 2014:3)

Al-Mushtaire, the biggest planet, Al-Mareekh, the sign of evil and bloodshed (Nair 2014:)

Anita Nair profusely makes use of names of flowers and birds in Malayalam in order to make her cosine taste like Kerala dinner. In book 1 of "Mistress", Anita Nair has not only borrowed and subtly interwoven Malayalam verbatim, like ari-poo 'a type of flower' but also she has made appropriate changes in case and plural markers as in the case of "wood-walled manjas" (Nair 2005:7). She talks about the song of karinkuyil 'black koel' and tuk-tuk sound of maramkothi 'wood pecker'.

The following quote from Srangi in Indian Novels in English: A Sociolinguistic Study has to be recalled in this context: "In case of literary Indian English, loan translations or word borrowings from the regional languages of the subcontinent are embedded in the English text, as markers pointing out a cultural distinctiveness. Lexicalness is a trade mark of Indian English canon."

Kachru (1980) in his article, "The Pragmatics of Non-native varieties of English", uses the term 'nativised' English for the English used by non-native writers who employ various linguistic devices to contextualize English in their own 'un-English' cultures. There is a relationship between the use of linguistic means in the nativization process that results in the acculturation of English. Kachru (1980) lists the linguistic devices employed by most writers for nativisation:

1) Lexical innovations: Many writers indulge in borrowing of words from local languages. Hybridization of words from distinct lexical sources is also a common feature, for instance work like 'lathi-charge', 'policewala', etc.

2) Translation equivalence: Many creative writers use translation from their mother tongue into English as one of the devices for correlating the speech event with its appropriate formal item, for example: "You spoiler of my salt" (approximate literal translation of 'namak haram' used by Mulk Raj Anand in Untouchable).

3) Contextual redefinition of lexical items of English in new contexts: Use of kinship terms, attitudinal terms.

4) Rhetorical and functional styles: Native style repertoire in English and non-native English literature thus acquire a distinct stylistic characteristic.

As Raja Rao himself pointed out in his preface to his novel Kanthapura, English is not a foreign tongue in India, but it is only the language of intellectual makeup not of our emotional make-up. His suggestion is that the Indian writer in English should learn to write Indian English and not 'Babu English' i.e. the English of Oxford. and Cambridge educated Englishmen. It is very difficult to express Indian sensibility in foreign tongue, nevertheless, Some eminent Indian writers in English like J. Nehru, Tagore, Gandhiji, R.K. Narayan, Mulk, Raj Anand and Raja Rao have overcome the problems and achieved international reputation.

\section{Deviation as the Literary Style}

Deviation "refers to linguistic moves away from conventions" (Busse 2014: 112). All the writers including the Indian English authors wanted to be distinguished from others by the style of their 
narration. Style itself is a deviation from normal course. The Indian English authors exploit the use of untranslatable terms to make their writing distinct form the other writers. So they select a situation for their narration which gives them amble scope to make use of the Indian native terms. The deviation from the use of culturally loaded untranslatable terms in the place of normal English terms is the devise they follow to make their rendering different form others. You will find deviation at all the levels of language such as discourse, syntax, morphology and lexicon.

\subsection{Deviation at the Discourse Level}

The Indian authors not only resort to code mixing in terms of words and phrases, they codes switches in the discourse level also. The novelists of Sudeep Nagarkar genre make their character code switching or use Hindi out rightly. The following are the instances from Sudeep Nagarkar's novels.

"Zindagi ko badalne me waqt nahi lagta, Par kabhi kabhi waqt ko badalne me zindagi lag jati hai!!" (You're the Password to My Life.)

"Bhaiya ek gold flake do" he said to chacha at tapir (Few things left unsaid.)

Also he makes character makes use of Hindi sentences with English mixing.

'Madam, aapka order garam karu kya?' the employee clarified in Hindi. (She swiped rightinto-my-heart)

There are many instances of code switching in Sudeep novels. His characters resort to code switching as exemplified in the following discourses.

you are my wife. tujhe dekh dekh sona.... (Few things left unsaid)

You will find many occasions where the entire discourse takes place in Hindi as exemplified below.

pyaar mein ashk bahate kyu hai...

do dil ek dusre ko tadpaate kyu hai...

kehte hai pyaar zindagi hai...

toh phir pyaar ko khel banate kyu hai (Few things left unsaid.)

Even Hindi songs interlude in discourse.

I started singing the song...

Lagta hai yeh kyu mujhe....sadiyo se chahu tujhe....

Lagta hai yeh kyu mujhe....sadiyo se chahu tujhe....

mere sapno me aake.....mujko apna banake....

Mujpe tu kar ehsaan....jiya dhadak dhadak ...jiya dhadak dhadak jaaye... (Few things left unsaid.)

Sudeep makes his novels dearer to the Hindi readers by making his character resort to code switching to Hindi. Sudeep appears to cooks his cuisine preferably to the taste of Hindi readers.

The following deviation found in Chettan's Half girl friend is interesting. The character himself admits "It was 90 per cent Bihari Hindi mixed with 10 per cent really bad English. For 
instance, this is what I had actually said: 'Cumty room...bat!aieyega zara? Hamara interview hai na wahan... Mera khel ka kota hai. Kis taraf hai?'

\subsection{Syntactic Deviation}

A stylistic feature that occurs frequently in all the literary works is the deviations or unique renderings in the syntax of sentences used to describe places or people or situation. Syntactic deviation is one of the characteristics that contributes to the 'literariness' of literary language. A characteristic feature of the syntax of literary language is deviation from grammatical norms.

Raja Rao's style is unique in the sense that he has tried to develop a variety of Indian English. He has written Kannada novel in English because words are Kannada but organization is English especially in Kanthapura. We find Kannada syntactic structure from the beginning itself in the novel. Here the writer has tried by means of sentence structures to reproduce the Kannada language spoken in the area of Karnataka.

E.g. High on the Ghats is it, high up the steep mountains that face the cool Arabian seas, up the Malabar coast is it,up Mangalore and Puttur and many a center of cardamom and coffee, rice and sugarcane.

The following sequence of verbless sentences describes the thoughts of Shayam in Mistress by Anita Nair.

The resorts in Southern Kerala have so much, Backwaters, Karimeen, Chinese Fishing

nets, Beaches, Plantations, Wildlife Sanctuaries. (Nair, 2005:160-161)

This is not the instance I am interested to bring out. The authors make efforts to show the difference in the style the language used by their characters. They want to show us the difference between the style of language used by the educated and uneducated or urban and rural. They try this 'untranslatability' by using certain deviant syntactic patterns alien to English but familiar to the regional language. The following examples are from Chetan Bagat's Three Mistakes of My Life.

You a party member? (instead of Are you a party member?)

You promised to help Mama, remember?

You know what are you doing, right?

The author ties to show that the syntax used by certain characters is based on the regional language. Chettan in his 'Half girlfriend' makes use of deviant syntactic constructions through a character hailing from Bihar. The following instance is interesting. Half girlfriend has many instances of deviant Bihari English introduced through a Bhari character Madhav.

'Me Madhav Jha from Dumraon, Bihar.' (Half girlfriend)

'Myself Madhav Jha.' (Half girlfriend)

\subsection{Lexical Deviation or Code Mixing}

A prominent stylistic feature is that these cross linguistic lexical terms code-mixed in the English narrative are neither italicized nor inserted within quotation marks as was the trend popularized by Indian English authors during the colonial and early postcolonial period. In the present day, the narratives are liberally sprinkled with words form Malayalam, Sanskrit, other regional South 
Indian languages like Tamil and Telugu and foreign languages like Italian, Somalian, Arabic and Dutch.

In code mixing, a fluent bilingual changes language during a conversation with another fluent bilingual, without any situational change whatsoever. The purpose seems to symbolize a somewhat ambiguous situation for which neither language on its own world would be right. This is a conversational code mixing which happens to quite a common phenomenon prevalent in today's globalized world. The following are the examples of code-mixing from Anita Nair's Mistress:

sunnath kalyanam 'circumcision ceremony'

veshakaaran 'performer/artiste'

taalam ' rhythm'

Apart from religious codes, the commonly used untranslatable terms are kinship terms. You will find regional kinship terms liberally used in Anita Nair's works. You come across the terms such as achan 'father', appachan 'father in Christian community', vaapa 'father in Muslim community', amma 'mother in Hindu community', ammachi 'mother in Christian community' umma 'mother in Muslim community', etta 'elder brother' and ikka 'elder brother in Muslim community' in her writings. Arunndhathi Roy too makes of Malayalam dictions including kinship term to add flavour to her cultural menu. The Malayalam oriented terms like Modalali Mariakutty, Kochamma, etc. are a few instances. Even the titles of the chapters are in Malayalam diction; say for example a chapter is titled as Kochu Thomban. Adding modifiers such as Kochu, Modalali, etc. is a typical way of forming addressing terms or proper names and it is a characteristic of Malayalam language. The Malayalam terms like Modalali Amma, Kochamma, etc. with the suffix amma 'woman' is a typical way of forming personal names in Malayalam. These Malayalam dictions add Malayalam flavour to the novel.

One may wonder about the reason for this kind of code mixing or using untranslatable terms in the English text. The reason can be easily guessed. The authors may be interested to present to the readers the cultural milieu in which the characters are placed in the textual world depicted by the authors. Or the authors many be interested to focus on the Indianness of the situation depicted in their writings.

You will find the regional terms like thampuran, thampurati, perumal, namboodiri, nair, menavan, gurukkal, aashaan, mash, haji, mullah, musaliyar, chaver pada, veshakaaran, modalali, jammi, sahiv, madam, karanavar, etc. in Anita Nair's work.

In Alphabet soup for Lovers Anita Nair present before us a code mixed language through a character called Komathi, who is a Tamil cook. Many Tamil lexis for food items are introduced to the readers: arisi appalam 'pappad made from raw rice power', badam paruppu 'almond', ceppankizhanggu 'yam', daangar chutney 'local name for a kind of 'raita', eeral 'mutton liver', filter kaapi 'filter coffee', godumai dosa 'dosa made from what batter', hayagriva 'sweet dish made form Bengal gram', Inji 'ginger', Jeera 'cumin seeds', karvepillai 'curry leaves', laddoo 'popular Indian sweet', murungakai 'drumstric', nande 'crab', oorkai 'pickle', paavakkai 'bitter gourd', quollu 'horse gram', rava 'semolina', soru 'shark', thayir 'curd' uzunthu 'black gram', varak 'gold/silver foil used to coat Indian sweets', wendiyum 'fenugreek' year 'prawn' zigarthanda 'cool milk drink popular in Madurai'.

Many of the food items mentioned above are untranslatable. The author exploits this satiation to add Indian flavour to her cuisine by giving the Tamil name as such in the English 
narration. The effort is a code mixing which has become a style of writing the author wants to dwell upon. You also find in this milieu the words from colloquial Tamil, cross linguistic lexical compounds, Telugu lexis, and Hindi lexis.

One may wonder whether such code mixed language is palatable to the readers. If one is not familiar with Tamil food items, one may not enjoy reading the code mixed language. One may be irritated sometimes. The English oriented transliteration using roman script for representing the food items is unreadable or understandable. It will be like eating cake with sambar. I wonder whether one will enjoy such a cuisine. If I am asked to compare, I would say I could not enjoy reading Anita Nair as I enjoyed R.K. Narayan's Malgudi days. One should have a balance in code mixing.

In Idris you will find Somali lexical items such as dhoocil and buub, eeye, sambuq, almas, etc. The author there by makes you a part and parcel of the plot she describes.

The above list of regional terms used in the English texts gives us the clue that Anita Nair set aside even a single opportunity of translating those terms into English. Instead she wants to keep the regional language terms to make it look like a native dinner with puttu or appam.

You also find instance in which Indian-English hybridized lexis are used. The following are the instances: America maa 'mother of America', tandava steps 'Lord Shiva's dance steps', filmi body 'body with film star', ghobr gas 'biogas', myna bird 'starling', nageswaram man 'man who plays trumpet or clarinet', rickshaw wallah 'person who pulls/drives rickshaw', tantric sex 'sexual movements'.

\subsection{Morphological Deviation}

One way of producing deviation at the morphological level by adding prefixes or suffixes to lexical items to which it would be normally affixed. In these hybrid narratives, grammatical features have crossed linguistic and national boundaries. Anita Nair's works show many instances of the above said morphological deviation. The suffix $-\mathrm{s}$, in both plural and possessive sense, is profusely used by the Nair with untranslated Malayalam words. For example, manjas, chavers, pulluvas, sambandams, Chevar Pada's etc.

\subsection{Phonological Deviation}

Certain Indian authors brings in characters speaking Indian English with Indianzied pronunciation.

You will find Raja Rao making phonological compromise in his writings. Besides using fricatives such as $\mathrm{f}, \mathrm{v}, \theta$, and $\partial$ Rao has used retroflex stops such as $t, d, \eta$ and $L$ in his novels. So we find the mixture of English and Kannaa speech sounds in his novels. As some characters are from Karnataka these speech sounds are common. So Rao has used these speech sounds also in his novels.

You will find many such instance in Chettan's Half girlfriend when his main character form Bihar speaks with typical Bihari accent or pronunciation. The following can be considered as an instance of phonological deviation at the discourse level as confessed by the character himself.

My English had sounded like this: 'Vood you laik to aarder anything?' (Would you like to order anything.) 


\section{Conclusion}

The linguistic analysis of the English writings of the Indian authors unfolds the devices used by them to make their work unique and the style they use is different from others. They vary in the amount of Indian ingredients they have made use of in their cuisine. They show distinction in the use of the untranslatable items which are culturally loaded. Some are very orthodox and they make use of Indian dictions with caution and restriction, whereas there are others who make use of Indian dictions profusely to make their work unique. As we have seen the place of the plot and the subject of the narration demands the use on Indian dictions by default. So the exploitation of use of untranslatable cultural items in the renderings of the Indian authors is inevitable. We have to make a distinction between the textual world and real world in order to consume what has been served to us.

\section{References}

Anand, Mulk Raj. (1948). Coolie. Bombay: Kutub-Popular.

Anand, Mulk Raj. (1960). The old woman and the crow. Bombay: Kutub-Popular.

Anand, Mulk Raj. (1960). The village. Bombay: Kutub-Popular.

Bandyopadhyay, Sumana. (2010). Indianisation of English: Analysis of Linguistic features in selected post1980 English Fictions. New Delhi: Concept Publishing Company Pvt. Ltd.

Bhagat, Chetan. (2008). The three mistakes of my life. New Delhi: Rupa Publications India Pvt. Ltd.

Bhagat, Chetan. (2014). Half girlfriend. New Delhi: Rupa Publications India Pvt. Ltd.

Bhatnagar, Manmohan K. (Ed.) (1996). Indian writings in English. New Delhi: Atlantic Publishers and distributers.

Biswas, Sarbojit and Das, Arindam. (2011). Introduction. In: Biswas, Sarbojit and Das, Arindam (Ed.) Colonial Specter and Beyond: Studies in Indian Writing in English. Kolkata: Books Way, xi-xvii.

Busse, Beatrix. (2014). Genre. In; Stockwell, P. and Whiteley, S. (Ed.) The Cambridge Handbook of Stylistics. Cambridge: Cambridge University Press.

Chatterjee, Sisir Kumar. (2004). Rushdie's use of language in Midnight's Children. In: Ray, Mohit K. (Ed.) Studies in ELT, Linguistics and Applied Linguistics. New Delhi: Atlantic Publishers, 146-162)

Crystal, David. (1987). The Cambridge Encyclopedia of Language. Cambridge: Cambridge University Press.

Crystal, David. (2006).Words, Words, Words. Oxford: Oxford University Press..

Dhar, T.N. (2012).Ethnicity, Identity, Literary imagination and the Indian English Novel. The Journal of Indian Writings in English.

Gavins, J. Text-world Theory: An Introduction. Edinburgh University Press.

Kachru, Braj. B. (1965). The Indianess of Indian English. Word, 21.391-410.

Kachru, Braj. B. (1980). The Pragmatics of non-native varieties of English. In: Smith, L.E. (ed.) English for Cross-cultural communication. London: Macmillan.

Kachru, Braj. B. The other tongue: English Across Cultures. University of Illinois Press.

Kachru, Braj. B. (2005). Asian Englishes Beyond the Canon. Oxford: Oxford University Press,

Mukherjee, Meenashi. (1971). The Twice Born Fiction. London: Heinemann Educational Books Ltd.

Nagarkar, Sudeep. (2011). A few things left unsaid. Srishti Publishers \& Distributors.

Nair, Anita. (2005). Mistress. New Delhi: Penguin Books India.

Nair, Anita. (2010). Malabar Mind. New Delhi: Harper Collins.

Nair, Anita. (2014).Idris: Keeper of the light. New Delhi: Harper Collins.

Nair, Anita. (2015). Alphabet Soup for lovers. New Delhi: Harper Collins.

Narayan, R.K. (1935). Swami and Friends. Hamish Hamilton.

Narayan, R.K. (1984). Tiger of Malgudi. Penguin Books.

Perry, John Olive. (1990). Is Indian English an "Alien Tongue”? In: The Literary Criterion Vol. XXVI. No.3.3855. 
Rao, Raja. (1938). Kanthapura. Bombay: Oxford University Press.

Rao, Raja. (1947). The Cow of the Barricades. Oxford University Press.

Rege, Josna E. (1997). "Victim into Protagonist? 'Midnight's Children' and the post-Rushie National Narratives of the Eighties". Studies in the Novel. 29 (3).

Rollason, Christopher. (2010). Indian Writing in English: Some language issues and translation problems. In: Prasad, G.J.V. (ed.) Translation and Culture: Indian Perspectives. New Delhi: Pencraft International.

Roy, Arundhati. 1997. The God of Small Things. India Ink.

Rushdie, Salman. (1981) Midnight's Children. Jonathan Cape.

Sanchita, J. (2016). Language, Culture and identity in selected works of Anita Nair and Meena Alexander: A Linguistic study. PhD thesis submitted to University of Kerala, Thiruvananthapuram.

Sarnagi, Jaydeep. (2005). Indian Novels in English: A Sociolinguistic Study. Bareilly: Prakash Book depot.

Shahane, Vasant. A. (1981). Indo-English Literature: Its Major Concerns and its Academic rationale in alien voice. In: Srivastava, A.K. (ed.) Aline Voice: Perspectives on commonwealth literature. Lucknow: Print house. 61-74.

Sharma, Devyani. (2012). Second language varieties: English in India. In: Bergs, Alexander and Brinton, Laurel J. (Ed.) English Historical linguistics: An international handbook volume 2. Berlin: De Gruyter, 2077-2209.

Spivak Chakravorty, Gayatri. (1990). Poststructuralism, marginality, postcoloniality and value. In: Collier, Peter and Geyer-Ryan, Helga (Ed.). Literary theory today. New York: Cornell University Press.

Rajendran Sankaravelayuthan is working as a Visiting Professor in Centre for Excellence in Computational Engineering and Networking (CEN), Amrita Vishwa Vidyapeetham, Coimbatore 641 112. 